\title{
Retractación: Evaluación nutricional del menú infantil ofrecido en servicios de comida rápida mediante análisis cuantitativo: un estudio de corte transversal
}

\author{
Diana Cárdenas, MD, $\mathrm{PhD}^{1}$ \\ Recibido: 20 de julio de 2021 \\ https://doi.org/10.35454/rncm.v4n4.332
}

Tras la publicación en redes sociales de la publicidad sobre la calidad nutricional de los menús infantiles de McDonald's, decidimos retractar la publicación del artículo "Evaluación nutricional del menú infantil ofrecido en servicios de comida rápida mediante análisis cuantitativo: un estudio de corte transversal"(1) (https://doi.org/10.35454/rncm.v4n3.224), escrito por las autoras Judith Consuelo Pardo Escallón y Adriana Pardo. La razón para la retractación fue el incumplimiento de la política de derechos de autor (https:// revistanutricionclinicametabolismo.org/index.php/ nutricionclinicametabolismo/licencia) al hacer un uso comercial del artículo y, adicionalmente, cuando la información contenida en la publicidad comparativa no refleja la realidad de lo expresado en el contenido del artículo.

La Revista de Nutrición Clínica y Metabolismo reconoce en todo momento que la empresa Arcos Dorados proporcionó los recursos económicos para la elaboración del análisis y las respectivas pruebas de laboratorio; no obstante, dicha colaboración económica no puede traducirse en una indebida utilización de los resultados de la investigación, por una parte, haciendo un uso comercial de la misma (lo cual incumple la política de derechos de autor de la Revista, como ya se mencionó) y, por otra parte, aseverando un contenido que en ningún momento es explícito dentro del artículo, pues este fue cuidadoso al no querer hacer público el nombre de las empresas,

Facultad de Medicina, Instituto de Investigación en Nutrición, Genética y Metabolismo, Universidad El Bosque, Bogotá, D.C, Colombia.

dianacardenasbraz@gmail.com por lo que utilizó códigos que identificaban cada uno de los menús analizados.

El uso comercial que se le dio al artículo y las afirmaciones contenidas en la publicidad comparativa viola las normas de derechos de autor de la Revista pues no refleja lo contenido en el artículo, ya que nunca se menciona de manera explícita dentro del artículo cual cadena de comida rápida tiene el mejor balance nutricional.

Por todo lo anterior, consideramos que no es ético darle uso comercial a un artículo que por normas de derechos de autor de la Revista no es permitido.

El propósito de la Revista con la publicación del artículo fue divulgar un análisis serio hecho por nutricionistas calificados sobre la evaluación cuantitativa de los menús infantiles, con el fin de mostrarle a la sociedad la evolución de las comidas rápidas. Este tema ha sido el objeto de diversos estudios recientes y es actualmente objeto de debate en la comunidad científica ${ }^{(2,3)}$.

Es importante mencionar que el artículo se publicó respetando las normas internacionales de ética en las publicaciones. Los autores declararon correctamente el conflicto intereses y la fuente de financiación. Las autoras declararon que la entidad financiadora no participó en el diseño, el análisis ni la redacción del manuscrito.

Por último, queremos hacer énfasis en que la Revista, editores, revisores, ni la ACNC reciben dinero por la publicación de los artículos (ver política de Open Access: https://revistanutricionclinicametabolismo.org/index. $\mathrm{php} /$ nutricionclinicametabolismo/licencia).

Seguiremos trabajando por una publicación rigurosa, científica y transparente que cumpla con los estándares 
internacionales de ética y buenas prácticas de las publicaciones.

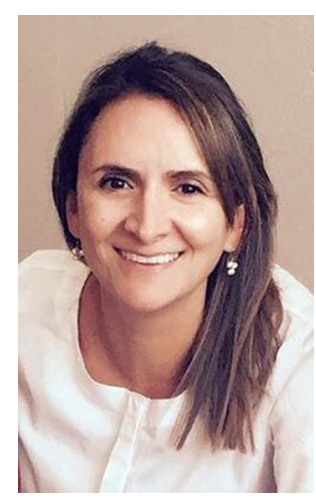

Diana Cárdenas, MD, PhD

Editora de la Revista de Nutrición Clínica y Metabolismo, ACNC. Profesora e investigadora del Instituto de Nutrición, Genética y Metabolismo, Facultad de Medicina, Universidad El Bosque, Bogotá, Colombia.

\section{Referencias bibliográficas}

1. Pardo Escallón J, Pardo A. Evaluación nutricional del menú infantil ofrecido en servicios de comida rápida mediante análisis cuantitativo: un estudio de corte transversal. Revista de Nutrición Clínica y Metabolismo. 2021:4(3):4-14. doi: $10.35454 /$ rncm.v4n3.224

2. Palos Lucio AG, Sansores Martínez DN, Olvera Miranda C, Quezada Méndez L, Tolentino-Mayo L. Nutritional Quality of Fast Food Kids Meals and Their Contribution to the Diets of School-Aged Children. Nutrients. 2020:26;12(3):612. doi: 10.3390/nu12030612.

3. Soo J, Harris JL, Davison KK, Williams DR, Roberto CA. Changes in the nutritional quality of fast-food items marketed at restaurants, 2010 v. 2013. Public Health Nutr. 2018; 21(11):2117-2127. doi: 10.1017/S1368980018000629. 